\title{
Tracheostomy in the management of patients with thermal injuries
}

\author{
Mónica Mourelo, Rita Galeiras, Sonia Pértega1', David Freire, Eugenia López², Javier Broullón³, \\ Eva Campos ${ }^{2}$
}

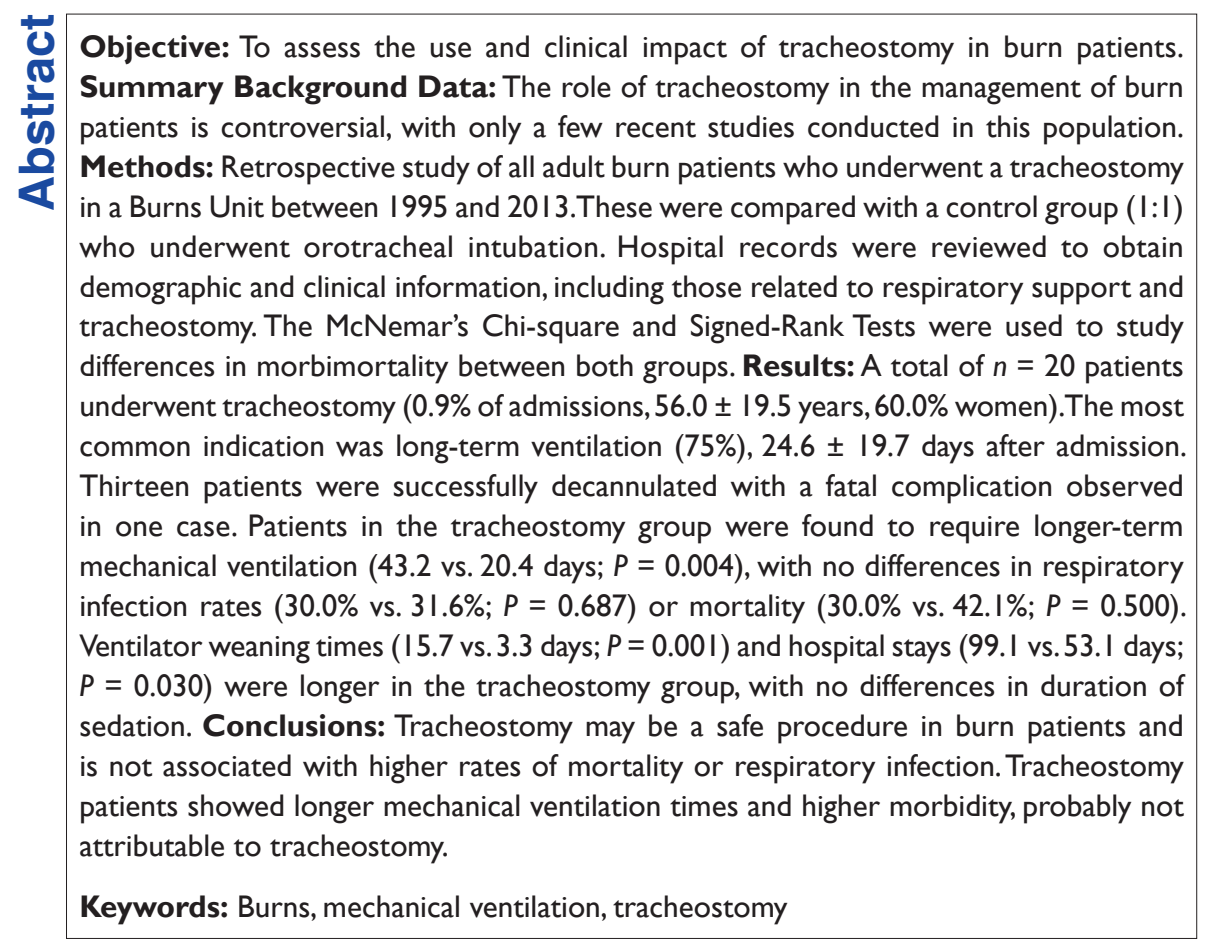

\begin{tabular}{|l|}
\hline Access this article online \\
\hline Website: www.ijccm.org \\
\hline DOI: 10.4103/0972-5229.162460 \\
\hline Quick Response Code: \\
\hline \\
\hline
\end{tabular}

\section{Introduction}

There is extensive literature regarding advances in the timing of tracheostomy, its safety and the techniques employed in populations of critically ill patients. ${ }^{[1-6]}$ However, the role of tracheostomy in the management of burn patients is somewhat controversial, and only a few recent studies have been conducted in this population. ${ }^{[7-12]}$ Most critical burn patients requiring

From:

Departments of Critical Care, ${ }^{1}$ Clinical Epidemiology and Biostatistics and ${ }^{3}$ Health Information Technology, University Hospital of A Coruna, A Coruña, 2Department of Plastic Surgery, Burn Unit, University Hospital of A Coruna, A Coruña, Spain

Correspondence:

Dr. Rita Galeiras, Burn Unit, University Hospital of A Coruna, SERGAS, As Xubias, 84, CP: 15006. A Coruña, Spain.

E-mail: ritagaleiras@ hotmail.es tracheal intubation can be successfully weaned and extubated without tracheostomy. The theoretical advantages of tracheostomy include minimizing dead space, facilitating bronchial hygiene, securing the airway, sometimes in emergency situations, and facilitating patient comfort. Head and neck burns and inhalation syndrome with upper and/or lower airway

This is an open access article distributed under the terms of the Creative Commons Attribution-NonCommercial-ShareAlike 3.0 License, which allows others to remix, tweak, and build upon the work non-commercially, as long as the author is credited and the new creations are licensed under the identical terms.

For reprints contact: reprints@medknow.com

How to cite this article: Mourelo M, Galeiras R, Pértega S, Freire D, López E, Broullón J, Campos E. Tracheostomy in the management of patients with thermal injuries. Indian J Crit Care Med 2015;19:449-55. 
involvement are not an indication for tracheostomy per se; neither are deep cervical burns a contraindication. There are currently no widely accepted guidelines on the prophylactic use of tracheostomy. ${ }^{[13,14]}$ We carried out a retrospective case-control study to evaluate the use and clinical impact of tracheostomy in terms of morbidity and mortality in patients with similar injuries.

\section{Methods}

A retrospective study of all adult burn patients ( $>18$ years) who underwent a tracheostomy while hospitalized in a Burns Unit between 1995 and 2013. These were compared with a control group comprising burn patients hospitalized in the same unit over the same period and who required mechanical ventilation. Controls were matched to cases according to a 1:1 ratio and variables related to the need for intubation and tracheostomy in this population, based on the current literature: (1) Percentage of total body surface area (\% TBSA) burned $(<20 \%, 20-39 \%, 40-59 \%$, $60-79 \%)$, (2) percentage of full-thickness body surface area (FTBSA \%) burned (<10\%, 10-19\%, 20-59\%, $\geq 60 \%$ ), (3) presence or absence of inhalation syndrome with upper and/or lower airway involvement, (4) neck involvement (yes/no). TBSA and FBSA cut-off points were selected according to categories previously associated with different risks of death in burn patients. ${ }^{[15]}$

Patients were identified based on Burns Unit records, regardless of the outcome. Where there were more than two possible controls, matching was based on their proximity at the time of admission. A total of $n=20$ patients with a tracheostomy were identified. In one case, matching was not possible (limited burn surface area with no inhalation syndrome or neck involvement, requiring mechanical ventilation over the following days due to heart failure).

Hospital records were reviewed to obtain demographic and clinical information. Data collected from the patients included demographic variables (age and gender), age-adjusted Charlson comorbidity index and injury-related variables: \% TBSA, \% FTBSA, presence of inhalation syndrome (upper and/or lower airway), neck involvement and mechanism of burn injury. Variables related to the need for respiratory support (mechanical ventilation time [days], duration of sedation [days], ventilator weaning time [days]) and tracheostomy (indication, timing and technique, duration in days, time to decannulation [days], and early/late complications) were also collected. The clinical status of the patient at the time of the procedure was recorded using the Sequential Organ Failure Assessment (SOFA) score. Further variables related to the clinical course: Number of required surgical interventions related to skin coverage; total number of infections, particularly respiratory (pneumonia and tracheobronchitis) and stomal infections, and primary or secondary bacteremia with any focus of infection. Finally, we recorded the length of stay (days), mortality during hospitalization and cause of death.

The definition of the infection was based on criteria linked to changes in organ failure and on the presence or suspicion of infection, clinically and/or microbiologically proven. Inhalation syndrome with upper airway injury was diagnosed where local damage could be observed by laryngoscopy. Inhalation syndrome with lower airway injury was diagnosed only where there were signs of inflammation in the lower airway. These included bronchoscopic evidence of inflammatory changes in the lower airway or the presence of soot in the tracheal aspirate. Because extensive burns per se are a risk factor for noncardiogenic pulmonary edema, the presence of the latter was not taken into account in the diagnosis of inhalation injury. The end of ventilation was defined as the time from which the patient no longer required any kind of respiratory support (such as continuous positive airway pressure) for 48 continuous hours. Decannulation was considered successful when achieved at the first attempt. All patients were weaned from the ventilator according to the standard unit protocol. The indication for tracheostomy was established based on prolonged mechanical ventilation ( $>21$ days on the ventilator) and difficult intubation. Surgical tracheostomy was performed by otorhinolaryngologist (ENT) specialists, whereas percutaneous tracheostomy was performed by intensivists at the bedside using the dissection plane method and since 2003, the Ciaglia Blue Rhino ${ }^{\circledast}$ percutaneous method without bronchoscopic guidance. The following tracheostomy-related complications were taken into consideration: Bleeding requiring surgical revision, false lumen, tracheoesophageal fistula, stomal infection and symptomatic tracheal stenosis. Those are occurring during the procedure or up to $48 \mathrm{~h}$ after its completion were considered early-stage. Monitoring was conducted by the ENT Department in cases where symptoms related to tracheostomy were present. The diagnosis of infection was at the physician's discretion, based on clinical symptoms and the diagnostic resources available at that time.

Tracheostomy and endotracheal intubated patients were compared in order to study differences in three primary outcomes: (a) Duration of mechanical ventilation, (b) incidence of respiratory infections and (c) Mortality. Secondary outcomes included: (a) Duration of 
weaning (days), (b) duration of sedation (days) and (c) length of hospital stay.

The study was performed with the approval of the Ethics Committee of our Institution.

\section{Statistical analysis}

A descriptive analysis was performed. Continuous variables were described as mean \pm standard deviation, median, and range. For qualitative variables, frequencies and percentages were computed.

Since patients with a tracheostomy were matched with controls, binary outcomes were analyzed using the McNemar Chi-square test for matched comparisons. The Signed-Rank Test was used for quantitative outcomes.

All $P$ values were two-tailed, and statistical significance was defined as $P<0.05$. All statistical analyses were performed using SPSS 19.0 (IBM Software Group, New York, USA) software.

\section{Results}

Tracheostomy was performed in $20(0.9 \%)$ of the 2212 patients admitted to the Burns Unit between 1995 and 2013, the percentage rising in recent years [Figure 1].

The mean age of these patients was $56.0 \pm 19.5$ years, and $60.0 \%$ were women. The most common mechanism of injury was flame burns, with a TBSA of $37.2 \pm 22.8$ and FTBSA of $33.0 \pm 19.4$. Inhalation syndrome was observed in $94.7 \%$ of patients, and neck involvement in $70.0 \%$. Mean SOFA score on admission was $2.4 \pm 1.9$. The age-adjusted Charlson comorbidity index score at admission was $2.2 \pm 2.0$ [Table 1].

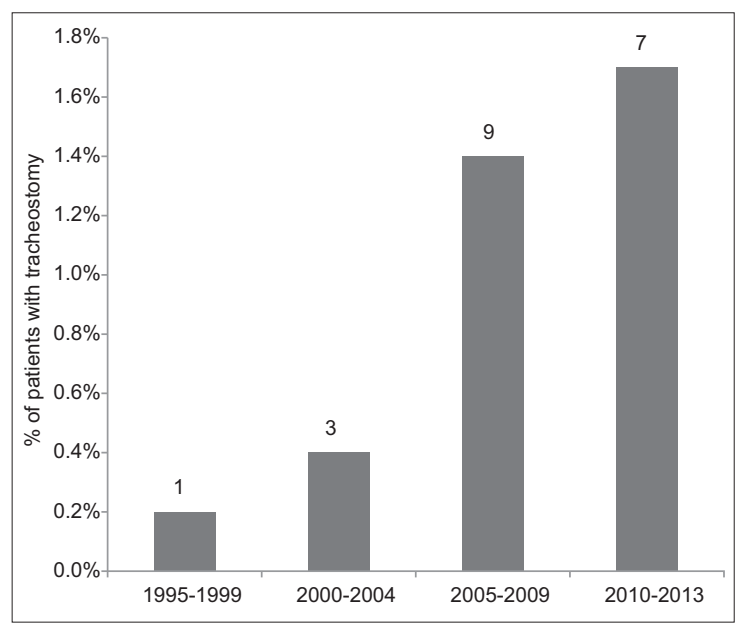

Figure I: Number of tracheostomies performed in burn patients, by year of admission
Tracheostomy-related characteristics are shown in Table 2. The main indication for tracheostomy was the need for prolonged mechanical ventilation. In $75 \%(n=15)$ of cases, the procedure was performed on a scheduled basis, with the percutaneous technique the procedure of choice in 13 patients. Indication for urgent tracheostomy in the remaining 5 patients was difficult intubation: In 3 patients tracheostomy was required on admission (one of them was initially assisted with Fast-Track ${ }^{\circledR}$ ), and two of them required tube withdrawal related to cuff leak. The mean time between admission and tracheostomy was $24.6 \pm 19.7$ days (range: 4.9-44.3). The mean SOFA score at the time of the procedure was $2.2 \pm 2.2$ (range: $0-4.4$ ). Surgical neck coverage was performed in $11(78.1 \%)$ of the 14 patients with involvement of the neck region, with tracheostomy performed before the coverage procedure in $36.4 \%$ of cases. Half of the patients were switched to a fenestrated catheter an average of $50.4 \pm 48.1$ days after undergoing

Table I: Characteristics of patients at admission to the burn unit who underwent tracheostomy versus those who did not

\begin{tabular}{|c|c|c|c|}
\hline & $\begin{array}{c}\text { Tracheostomy } \\
\text { patients } \\
(n=20)(\%)\end{array}$ & $\begin{array}{c}\text { Intubated } \\
\text { patients } \\
(n=19)(\%)\end{array}$ & $P^{*}$ \\
\hline \multicolumn{4}{|l|}{ Age (years) } \\
\hline Mean $\pm S D$ & $56.0 \pm 19.5$ & $45.7 \pm 22.2$ & 0.113 \\
\hline Median & 56 & 40 & \\
\hline \multicolumn{4}{|l|}{ Gender } \\
\hline Male & $8(40.0)$ & $7(36.8)$ & 0.999 \\
\hline Female & $12(60.0)$ & $12(63.2)$ & \\
\hline \multicolumn{4}{|l|}{$\begin{array}{l}\text { Age-adjusted charlson } \\
\text { comorbidity index }\end{array}$} \\
\hline Mean \pm SD & $2.2 \pm 2.0$ & $1.5 \pm 2.1$ & 0.370 \\
\hline Median & 0 & 0 & \\
\hline \multicolumn{4}{|l|}{ Inhalation syndrome } \\
\hline No & $2(5.3)$ & $2(10.0)$ & 0.999 \\
\hline Upper airway injury & $8(42.1)$ & $8(40.0)$ & \\
\hline Upper and lower airway injury & $10(52.6)$ & $10(50.0)$ & \\
\hline \multicolumn{4}{|l|}{ TBSA burned (\%) } \\
\hline Mean \pm SD & $37.2 \pm 22.8$ & $41.5 \pm 23.0$ & 0.076 \\
\hline Median & 30 & 35.0 & \\
\hline$<20 \%$ & $5(25.0)$ & $4(2 \mathrm{I} . \mathrm{I})$ & \\
\hline $20-39 \%$ & $6(30.0)$ & $6(3 \mid .6)$ & \\
\hline $40-59 \%$ & $3(I 5.0)$ & $3(I 5.8)$ & \\
\hline $60-79 \%$ & $6(30.0)$ & $6(31.6)$ & \\
\hline \multicolumn{4}{|l|}{ FTBSA burned (\%) } \\
\hline Mean $\pm S D$ & $33.0 \pm 19.4$ & $35.5 \pm 20.0$ & 0.255 \\
\hline Median & 30 & 30.0 & \\
\hline$<10 \%$ & $3(15.0)$ & $2(10.5)$ & \\
\hline $10-19 \%$ & $2(10.0)$ & $2(10.5)$ & \\
\hline $20-59 \%$ & II (55.0) & II (57.9) & \\
\hline$\geq 60 \%$ & $4(20.0)$ & $4(2 I . I)$ & \\
\hline \multicolumn{4}{|l|}{ Neck involvement } \\
\hline No & $6(30.0)$ & $5(26.3)$ & 0.999 \\
\hline Yes & $14(70.0)$ & $14(73.7)$ & \\
\hline \multicolumn{4}{|l|}{ Mechanism of injury } \\
\hline Flame & $18(90.0)$ & $19(100)$ & $N / A$ \\
\hline Other & $2(10.0)$ & $0(0)$ & \\
\hline
\end{tabular}

* $P$ value was calculated comparing 19 matched case-control pairs. TBSA: Total body surface area; FTBSA: Full-thickness body surface area; SD: Standard deviation; N/A: Not available 
tracheostomy. In terms of tracheostomy outcome, $13(65.0 \%)$ patients were successfully decannulated. The mean time from the end of mechanical ventilation to decannulation was $48.4 \pm 44.5$ days. Of 7 patients (35\%) who were not decannulated, six died needing the device and one was transferred to another hospital requiring cannulation. One patient died as a result of accidental displacement of the device. Other than this problem, no early or late symptomatic complications were registered that required follow-up by the ENT Department.

Patients with a tracheostomy were compared with 19 matched control patients as previously described. As can be seen from Table 1, both patient groups were also similar in age, gender, comorbidity score, and mechanism of injury.

Outcome variables were compared between cases and controls [Table 3]. Patients in the tracheostomy group were found to require longer-term mechanical ventilation (43.2 vs. 20.4 days; $P=0.004$ ), whereas no differences were found in the incidence of respiratory infection $(30.0 \%$ vs. $31.6 \% ; P=0.687)$ or mortality $(30.0 \%$ vs. $42.1 \% ; P=0.500)$. None of these patients presented more than one respiratory infection episode. The incidence of respiratory infection observed after tracheostomy was $16.6 \%$. As regards secondary outcomes, ventilator weaning times were significantly longer in the tracheostomy group than in the endotracheal intubation group (15.7 vs. 3.3 days; $P=0.001$ ). Hospital stays were likewise significantly longer in patients with a tracheostomy ( 99.1 vs. 53.1 days; $P=0.030$ ). No significant differences were observed in the duration of sedation. In both groups, the most common cause of death was a shock ( $83.3 \%$ vs. $87.5 \%$, respectively) [Figure 2].

The number of episodes of infection per patient was significantly higher in the tracheostomy group with $2.1 \pm 1.1$ episodes, versus $0.9 \pm 0.8$ episodes in the control group. The same was true for patients with bacteremia, with $1.7 \pm 1.1$ episodes per patient versus $1.3 \pm 0.5$, respectively. No cases of stomal infection were registered. The number of surgical procedures was significantly higher in the tracheostomy group, with an average of $3.3 \pm 2.0$ procedures performed versus $1.9 \pm 2.1$ in the control group [Table 4].

\section{Discussion}

This study compared 20 burn patients who received a tracheostomy versus 19 patients with similar injuries who did not. There were no differences in terms of age or comorbidity between the two groups. The indication criteria for this procedure were inability to intubate
Table 2: Tracheostomy-related characteristics

\begin{tabular}{|c|c|c|c|}
\hline & $n(\%)$ & Mean \pm SD & Median \\
\hline Duration of tracheostomy (days) & & $24.6 \pm 19.7$ & 24.0 \\
\hline Days of ventilation days before tracheostomy & & $23.3 \pm 18.4$ & 24.5 \\
\hline \multicolumn{4}{|l|}{ Indication for tracheostomy } \\
\hline Prolonged intubation & $15(75)$ & & \\
\hline Difficult intubation & $5(25)$ & & \\
\hline \multicolumn{4}{|l|}{ “Timing” } \\
\hline Urgent & $5(25)$ & & \\
\hline Elective & $15(75)$ & & \\
\hline \multicolumn{4}{|l|}{ Tracheostomy technique } \\
\hline Percutaneous & $13(65)$ & & \\
\hline Surgical & $7(35)$ & & \\
\hline SOFA on the day of tracheostomy & & $2.2 \pm 2.2$ & 2 \\
\hline \multicolumn{4}{|l|}{ Surgical neck coverage } \\
\hline Nonsurgical & $3(21.4)$ & & \\
\hline Prior to tracheostomy & $4(28.6)$ & & \\
\hline Same or postintervention tracheostomy & $7(50.0)$ & & \\
\hline Days to switch to fenestrated catheter & & $50.4 \pm 48.1$ & 40.0 \\
\hline $\begin{array}{l}\text { Days without mechanical ventilation before } \\
\text { decannulation }\end{array}$ & & $48.4 \pm 44.5$ & 35.0 \\
\hline
\end{tabular}

SOFA: Sequential Organ Failure Assessment; SD: Standard deviation

Table 3: Outcomes of study patients

\begin{tabular}{|c|c|c|c|}
\hline & $\begin{array}{c}\text { Tracheostomy } \\
\text { patients } \\
(n=20)(\%)\end{array}$ & $\begin{array}{l}\text { Intubated } \\
\text { patients } \\
(n=19)(\%)\end{array}$ & $P^{*}$ \\
\hline \multicolumn{4}{|l|}{ Primary outcomes } \\
\hline \multicolumn{4}{|l|}{ Duration of MV (days) } \\
\hline Mean \pm SD & $43.2 \pm 72.2$ & $20.4 \pm 16.8$ & 0.004 \\
\hline Median & 35.5 & 20 & \\
\hline Incidence of respiratory infection & $6(30.0)$ & $6(31.6)$ & 0.687 \\
\hline Mortality & $6(30.0)$ & $8(42.1)$ & 0.500 \\
\hline \multicolumn{4}{|l|}{ Secondary outcomes } \\
\hline \multicolumn{4}{|l|}{ Duration of weaning (days) } \\
\hline Mean $\pm S D$ & $15.7 \pm 15.6$ & $3.3 \pm 6.5$ & 0.001 \\
\hline Median & II.5 & I & \\
\hline \multicolumn{4}{|l|}{ Duration of sedation (days) } \\
\hline Mean \pm SD & $27.7 \pm 21.2$ & $17.1 \pm 16.3$ & 0.107 \\
\hline Median & 27.0 & 14 & \\
\hline \multicolumn{4}{|l|}{ Length of hospital stay (days) } \\
\hline Mean $\pm S D$ & $99.1 \pm 78.5$ & $53.1 \pm 56.5$ & 0.030 \\
\hline Median & 76.5 & 35.0 & \\
\hline
\end{tabular}

*P value were calculated comparing 19 matched case-control pairs. MV: Mechanical ventilation; SD: Standard deviation

or extubate beyond 3 weeks, although the timing was individualized based on the patient's clinical condition.

The most important findings in this study were as follows:

First: Among critical burn patients, those with a tracheostomy showed no significant differences in mortality compared to the endotracheal intubation group. Seventy percent of patients with a tracheostomy were alive at discharge. Our study included patients in whom percutaneous tracheostomy was performed due to impossible translaryngeal intubation, where the procedure can be life-saving. However, the findings also suggest the need to be able to identify patients likely to 


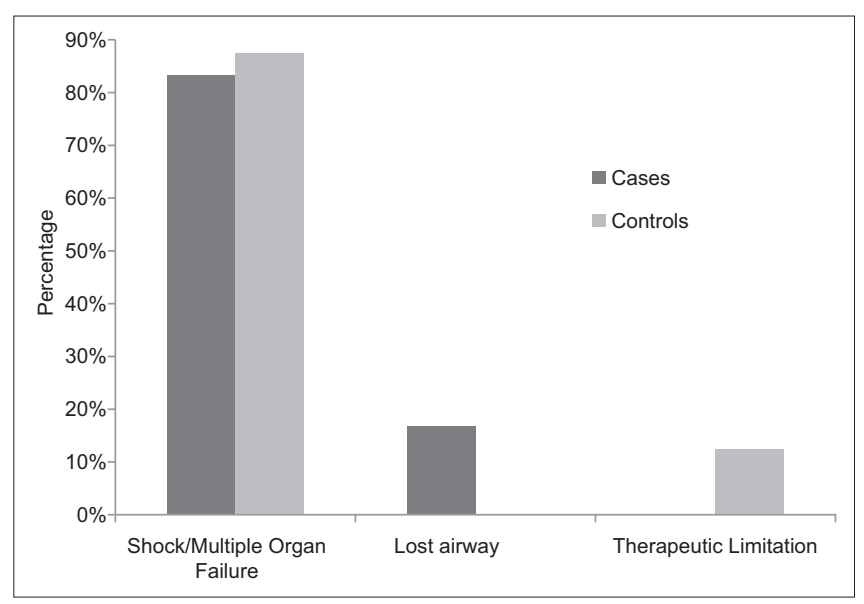

Figure 2: Causes of death in tracheostomy and endotracheal intubated patients

Table 4: Surgical procedures and infections in patients who did or did not undergo tracheostomy

\begin{tabular}{|c|c|c|c|}
\hline & $\begin{array}{c}\text { Tracheostomy } \\
\text { patients } \\
(n=20)(\%)\end{array}$ & $\begin{array}{c}\text { Intubated } \\
\text { patients } \\
(n=19)(\%)\end{array}$ & $\boldsymbol{P}$ \\
\hline \multicolumn{4}{|l|}{ Infection episodes } \\
\hline Mean \pm SD & $2.1 \pm 1.1$ & $0.9 \pm 0.8$ & 0.004 \\
\hline Median & 2.0 & I & \\
\hline Incidence of respiratory infection & $6(30.0)$ & $6(31.6)$ & 0.687 \\
\hline $\begin{array}{l}\text { Incidence of respiratory infection } \\
\text { post tracheostomy }\end{array}$ & I (I6.6) & - & - \\
\hline \multicolumn{4}{|l|}{ Respiratory infection episodes } \\
\hline Mean $\pm S D$ & $\mathrm{I} \pm 0$ & $\mathrm{I} \pm 0$ & 0.999 \\
\hline Median & I & I & \\
\hline Incidence of bacteremia & $15(75)$ & $7(36.8)$ & 0.039 \\
\hline $\begin{array}{l}\text { Incidence of bacteremia post } \\
\text { tracheostomy }\end{array}$ & II (55) & - & - \\
\hline \multicolumn{4}{|l|}{ Bacteraemia episodes } \\
\hline Mean \pm SD & $1.7 \pm 1.1$ & $1.3 \pm 0.5$ & 0.010 \\
\hline Median & I & 1 & \\
\hline \multicolumn{4}{|l|}{ Surgical procedures } \\
\hline Mean \pm SD & $3.3 \pm 2.0$ & $1.9 \pm 2.1$ & 0.034 \\
\hline Median & 3 & 1 & \\
\hline
\end{tabular}

have reasonably good results after prolonged ventilatory support requiring the placement of a tracheostomy. In a prospective, nonrandomized study with unpaired patients from the control group, Eckhauser et al. ${ }^{[16]}$ found that all patients with a tracheostomy died, versus $25 \%$ mortality in patients without a tracheostomy, which led the authors to consider that the injudicious use of this procedure can be fatal. A subsequent study ${ }^{[17]}$ in which 99 tracheostomies were reviewed in patients admitted to a single hospital, mortality did not appear greater in patients with a tracheostomy. Neither were any differences in mortality observed in a retrospective audit conducted by Aggarwal et al.,$^{[8]}$ although in patients with more than $60 \%$ TBSA burns, survival was found to be higher in those who received tracheostomy.
Second: Tracheostomy was associated with increased morbidity. Patients with tracheostomies had longer hospital stays and required more days of mechanical ventilation. These cases were observed to require more debridement and grafting procedures, their clinical course showing a higher incidence of infections and bacteremia episodes, which could be related to the greater number of urinary or vascular devices used during hospitalization, although this was not analyzed. We believe that this reflects a disparity in the clinical course between the groups which is not attributable to tracheostomy. In fact, the rate of respiratory infections (pneumonia and tracheobronchitis) was similar in both groups. The greater percentage of percutaneous procedures in our study and current supportive care methods may also explain the low incidence of pneumonia associated with a tracheostomy, as suggested in the literature. ${ }^{[7,17]}$ In the studies by Isaev ${ }^{[18]}$ and Jones et al. ${ }^{[17]}$ too, the incidence of pneumonia was similar in patients with a tracheostomy and those without. In a retrospective study, Aggarwal et al ${ }^{[8]}$ concluded that tracheostomy was associated with a higher prevalence of respiratory infection, suspecting multifactorial causes likely related to the high incidence of inhalation, larger burn size and prolonged mechanical ventilation in their study. Infectious bronchopulmonary complications constitute a threat in burn patients, particularly when the tracheostomy is placed through a deep burn area. However, in our study, only one cervical burn patient presented with this event after undergoing the procedure. In the study by Gravvanis et al., ${ }^{[7]}$ all patients who developed pneumonia had neck burns, pointing to the close correlation between cervical burns, tracheostomy, and pulmonary sepsis. In a postmortem pulmonary pathology study in burn patients, Foley, et al. ${ }^{[19]}$ found that respiratory complications appeared more related to tracheostomy than to facial burns or inhalation.

There is not enough evidence in the literature to conclude that early tracheostomy is associated with the shorter ventilatory support. Our study does not allow to see the impact of early tracheostomy in this indicator because the median number of days of mechanical ventilation to tracheostomy was 24.5 . In the study by Hunt et al., ${ }^{[20]}$ the authors considered that the timing of the procedure should be individualized and based on the clinical condition of the patient. In the study by Saffle et al., ${ }^{\left[{ }^{[9]}\right.}$ early tracheostomy did not reduce the duration of mechanical ventilation, length of stay or mortality rate.

Even though patients with a tracheostomy required more days of mechanical ventilation, no differences 
were found in the number of days of sedation. This may suggest that tracheostomy improves patient tolerance to prolonged mechanical ventilation. However, it did not allow earlier resumption of oral nutrition in the tracheostomy group. The study by DuBose et al. ${ }^{[11]}$ showed that the delay in resuming oral feeding correlates with \% TBSA, the number of days of mechanical ventilation and days with a tracheostomy, which may suggest that patients who require prolonged intubation or a tracheostomy are at high risk of dysphagia, as also concluded by Clayton et al..$^{[12]}$

Our results show that patients with a tracheostomy had longer weaning times. Factors such as the presence of critical illness polyneuropathy, slow recovery from a process involving organ dysfunction, anxiety due to prolonged ventilator dependence, multifactorial anemia or cardiac dysfunction could all explain a more gradual weaning strategy. Decannulation was well-tolerated in 13 of the 14 patients who survived, half of whom had been fitted with a fenestrated device to facilitate bronchial hygiene and improve patient communication.

Third: In our study, there were no significant complications related to the procedure, and not a single patient required surgical revision, although one case of accidental displacement of the device was registered which proved fatal. We learned that when the procedure is performed in the days immediately after sustaining burns, in patients with burns of the face and neck, soft tissue swelling distorts anatomical landmarks, rendering the procedure technically more difficult and causing the distance between the skin and trachea to possibly require a longer tracheostomy tube, now available, in order to prevent the device from coming out of the trachea. The low incidence of mechanical complications in our series suggests that despite this being an anatomically complex patient population for the percutaneous approach, the use of a bronchoscope is not routinely required, although it may be useful in selected patients. Differences in the incidence of early complications compared to other documents in the literature were probably due to the greater number of percutaneous tracheostomies or changes related to the design of the devices. Employing the technique under optimal clinical conditions also increases the safety of the procedure (mean SOFA score: 2.2).

Methodological limitations of this study included its small sample size and retrospective design. This was a retrospective case-control study assessing the use, complications and outcomes of tracheostomy in burn patients. Ideally, a prospective randomized clinical trial with a higher number of patients comparing the outcomes of endotracheal intubation and tracheostomy should be performed in order to obtain conclusive results.

The results may have been affected by selection bias. All burn patients who underwent a tracheostomy during the study period were included. Given that those with more severe injuries may have been more likely to have a tracheostomy, as was the case in other studies, ${ }^{[8,9,16]}$ cases were matched with controls by \% TBSA, \% FTBSA, inhalation syndrome, and neck involvement. Matching prevents confounding bias, allowing to assess the relationship between tracheostomy and morbimortality having already taken matching variables into account so that there is no need to adjust for these variables in the analysis. Finally, information bias is another common problem in case-control studies. Since the information was collected retrospectively from clinical records, the quality of the data may be limited. However, if said bias is indeed present, it is expected to affect both patient groups equally.

Prospective multi-center studies are needed in the critically burned patient population to help identify those patients who should have a tracheostomy, and the most suitable time to perform the procedure. Define those patients who may require prolonged mechanical ventilation is the first step. What is better defined is the equivalence of the techniques to perform this procedure.

Although this study may be limited by its small sample size, it provides up-to-date results on the controversial use of tracheostomy in burn patients. Our study suggests that critical burn patients with a tracheostomy had no increased mortality, even though the procedure was performed in patients with increased morbidity and making greater use of hospital resources. Tracheostomy did not increase the incidence of respiratory infections, and both early and late complications were rare.

\section{Financial support and sponsorship}

Nil.

\section{Conflicts of interest}

There are no conflicts of interest.

\section{References}

1. Young D, Harrison DA, Cuthbertson BH, Rowan K, TracMan Collaborators. Effect of early vs late tracheostomy placement on survival in patients receiving mechanical ventilation: The TracMan randomized trial. JAMA 2013;309:2121-9.

2. Terragni PP, Antonelli M, Fumagalli R, Faggiano C, Berardino M, 
Pallavicini FB, et al. Early vs late tracheotomy for prevention of pneumonia in mechanically ventilated adult ICU patients: A randomized controlled trial. JAMA 2010;303:1483-9.

3. Angus DC. When should a mechanically ventilated patient undergo tracheostomy? JAMA 2013;309:2163-4.

4. Freeman BD, Morris PE. Tracheostomy practice in adults with acute respiratory failure. Crit Care Med 2012;40:2890-6.

5. Koch T, Hecker B, Hecker A, Brenck F, Preuß M, Schmelzer T, et al. Early tracheostomy decreases ventilation time but has no impact on mortality of intensive care patients: A randomized study. Langenbecks Arch Surg 2012;397:1001-8.

6. Blot F, Similowski T, Trouillet JL, Chardon P, Korach JM, Costa MA, et al. Early tracheotomy versus prolonged endotracheal intubation in unselected severely ill ICU patients. Intensive Care Med 2008;34:1779-87.

7. Gravvanis AI, Tsoutsos DA, Iconomou TG, Papadopoulos SG. Percutaneous versus conventional tracheostomy in burned patients with inhalation injury. World J Surg 2005;29:1571-5.

8. Aggarwal S, Smailes S, Dziewulski P. Tracheostomy in burns patients revisited. Burns 2009;35:962-6.

9. Saffle JR, Morris SE, Edelman L. Early tracheostomy does not improve outcome in burn patients. J Burn Care Rehabil 2002;23:431-8.

10. Kagan RJ, Gamelli R, Kemalyan N, Saffle JR. Tracheostomy in thermally injured patients: Does diagnosis-related group 483 adequately estimate resource use and hospital costs? J Trauma 2004;57:861-6.
11. DuBose CM, Groher MG, Mann GC, Mozingo DW. Pattern of dysphagia recovery after thermal burn injury. J Burn Care Rehabil 2005;26:233-7.

12. Clayton N, Kennedy P, Maitz P. The severe burns patient with tracheostomy: Implications for management of dysphagia, dysphonia and laryngotracheal pathology. Burns 2010;36:850-5.

13. Gotsman MS, Whitby JL. Respiratory infection following tracheostomy. Thorax 1964;19:89-96.

14. Moylan JA Jr, West JT, Nash G, Bowen JA, Pruitt BA Jr. Tracheostomy in thermally injured patients: A review of five years' experience. Am Surg 1972;38:119-23.

15. Galeiras R, Lorente JA, Pértega S, Vallejo A, Tomicic V, de la Cal MA, et al. A model for predicting mortality among critically ill burn victims. Burns 2009;35:201-9.

16. Eckhauser FE, Billote J, Burke JF, Quinby WC. Tracheostomy complicating massive burn injury. A plea for conservatism. Am J Surg 1974;127:418-23.

17. Jones WG, Madden M, Finkelstein J, Yurt RW, Goodwin CW. Tracheostomies in burn patients. Ann Surg 1989;209:471-4.

18. Isaev GA. On the indications and effectiveness of tracheostomy in the treatment of burns. Khirurgiia (Mosk) 1968;44:80-2.

19. Foley FD, Moncrief JA, Mason AD Jr. Pathology of the lung in fatally burned patints. Ann Surg 1968;167:251-64.

20. Hunt JL, Purdue GF, Gunning T. Is tracheostomy warranted in the burn patient? Indications and complications. J Burn Care Rehabil $1986 ; 7: 492-5$. 